\title{
Compilation of the Scale of College Students' Attitudes towards Three-self-determination PE Class and Norm Construction
}

\author{
Yiyong $\mathrm{Wu}^{1}$, Rong Hai Su ${ }^{2^{\star}}$ \\ ${ }^{1}$ Business School, Minnan Normal University, Fujian, CHINA \\ 2 School of Physical Education and Sport, Beijing Normal University, Beijing, CHINA
}

Received 27 December 2017 - Revised 13 February 2018 - Accepted 25 March 2018

\begin{abstract}
College students' attitudes towards three-self-determination PE class are preceded the theoretical construction and the scale of college students' attitudes towards three-selfdetermination PE class is compiled by comprehensively applying literatures, discussions, and questionnaire. With Partial Least Squares (PLS) to select information and explore theories, it reveals that college students' attitudes towards three-selfdetermination PE class are composed of 7 dimensions of attitudes towards course cognition, attitudes towards social behavior, attitudes towards health and safety, attitudes towards leisure life, attitudes towards sports knowledge, attitudes towards sports technique, and attitudes towards physical development; and, the fit of attitude model is favorable. With Structural Equation Modeling (SEM) Confirmatory Factor Analysis, the structure of the scale of college students' attitudes towards three-selfdetermination PE class is supported, and the scale presents good reliability, validity, and stability. What is more, the national overall, gender, and grade norms are also constructed.
\end{abstract}

Keywords: three-self-determination teaching, PE class, partial least squares, structural equation modeling, norm

\section{INTRODUCTION}

According to the spirit of "National Teaching Guidelines for PE Course at the Level of General Universities and Colleges", three-self-determination PE teaching model thoroughly develops the student-centered and teacher-led functions to promote open instruction and expand the time and space of PE course. Under the guide of teachers, students select the class contents (projects), the instructor, and the time for the class. Wu (2011) took the students in academic years of 2008 and 2009 in 8 general colleges and universities in Fujian Province as the research subjects and received the feedback that $83.6 \%$ students regarded the necessity of three-self-determination teaching. Apparently, three-self-determination teaching model was deeply approved by students. In terms of teaching mode, three-self-determination teaching model expands the time and space of PE course, could satisfy most students' requirements for class selection, and is suitable and correct. Nevertheless, has three-self-determination teaching model, which has been practiced since 2002, achieved the expected teaching goal? What are students' attitudes after receiving three-self-determination teaching model? What is the effect of formed attitudes on three-selfdetermination PE class teaching effectiveness? Such questions should be emphasized in order to better understand the actual effect of three-self-determination PE class teaching model. Regarding attitudes towards PE class, more questionnaire surveys are applied to the measurement. International scales of attitudes towards PE class are basically complied with Wear's Likert, while domestic research on attitudes towards PE class mainly combines the relations with interests, motivation, and behaviors or focuses on descriptive surveys that the research quality needs to be enhanced. From literature review, there has not been a scale of attitudes established aiming at PE class domestically.

(C) 2018 by the authors; licensee Modestum Ltd., UK. This article is an open access article distributed under the terms and conditions of the Creative Commons Attribution License (http://creativecommons.org/licenses/by/4.0/).

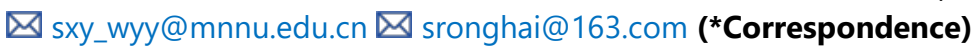




\section{Contribution of this paper to the literature}

- Colleges and universities should reinforce the research on the modernization of course establishment, timely assign teachers for learning and study, and establish some emerging PE projects to expand the course establishment, enhance the course novelty, and satisfy students' needs.

- The network of "three-self-determination" course selection should be reinforced to enhance the teaching organization and management. The single assessment model should be changed to stress on the comprehensive evaluation in order to provide larger free space for students.

- Colleges and universities should grasp such an opportunity to enlarge the PE field and facilities and gradually release the contradiction between students' requirement for course establishment and the lag of field and facility construction.

For this reason, in order to understand college students' attitudes towards physical education after receiving three-self-determination PE class and test college three-self-determination teaching model, a reliable and effective scale of college students' attitudes towards three-self-determination PE class is complied for the reference.

\section{LITERATURE REVIEW}

Since Alden (1932) studied the least attractive factors in female college students' attitudes towards physical education in 1932, research on students' attitudes towards PE class has been broadly concerned. In the $20^{\text {th }}$ century before 1940s, research on students' attitudes towards PE class was restricted to questionnaire survey, and there was not a researcher compiling the scale of attitudes towards PE class. Not until 1945, when Carr (1945) compiled the first scale of attitudes towards physical education with interval scale, or Thurstone Scale, did foreign researchers started the research on and application to the scale of attitudes towards PE class.

Reviewing domestic and international research on students' attitudes towards PE class, most research revealed that students approved or presented active attitudes towards PE class, supported the social, affective, and physical value of PE class to students, and improved the attitudes towards physical education taking PE course. Particularly, in the $20^{\text {th }}$ century after 1990s, attitudes showed the critical role in the research on PE teaching, mainly because attitudes were the key factor in adolescents participating in PE activity.

In regard to the measurement of attitudes, which cannot be directly measured, domestic and international researchers mainly measured students' attitudes towards PE class indirectly, e.g. personal interview, questionnaires, evaluation method, and project method, where questionnaires were mostly applied to measure students' attitudes towards PE class. Regarding the types of attitude scales, current application of attitude scales contains Thrustone scale (or interval scale), Likert scale (or summated scale), and Guttman scale (or cumulative scale), where Likert scale, with the advantages of broader measurement and application, simpler measurement practice, better conforming to the requirement for reliability, and more delicate and deeper measurement, is favored by domestic and international researchers. Domestic and international researchers present different aspects on the structure of students' attitudes towards PE class. Most researchers discussed attitude structure with social psychology and considered that attitudes were composed of cognition, affection, and behavioral intention. Other researchers studied attitude structure from the aspect of Theory of Reasoned Action and regarded past behaviors and experiences as the key factors in attitudes. Some researchers directly applied the structure of attitudes towards physical education to the evaluation of students' attitudes towards PE class. A lot of researchers took the elements of PE teaching, e.g. teachers, class contents, teaching climate, and teaching goal, into the account of attitude structure.

No matter which measurement is applied, which type of scale is applied, and what the structure of scale is, the quality of test tools should be guaranteed, as it could directly affect the description or inference of research results. As a matter of fact, research methods on sports science were emphasized after 2000; especially, the popularity of Structural Equation Modeling (SEM) had the scale compilation process become stricter. The overall reliability and validity of the scale of students' attitudes towards PE class were also enhanced. From the development of the scale of attitudes towards PE class in the past 86 years, the research on attitudes towards PE class has developed from borrowing the scale of research on attitudes towards physical education to general research on attitudes towards PE class and would develop to the research on attitudes with PE class teaching characteristics. Based on the understanding and above descriptions, Likert scale is utilized in this study. Based on the attitude theory in social psychology and combined with the statement of college three-self-determination PE class teaching goals, the scale of attitudes towards college three-self-determination PE class is compiled for analyzing the reliability and validity and establishing the norm. 


\section{PRETEST OF THE SCALE OF ATTITUDES TOWARDS THREE-SELF- DETERMINATION PE CLASS}

\section{Pretest Subject}

With group sampling, colleges and universities with three-self-determination physical education are distributed the pretest scale, including Peking University, Sichuan University, Shenzhen University, Northeast Normal University, Northwestern Polytechnical University, and Southeast University. Total 508 copies of questionnaire are distributed. Respondents who have never taken three-self-determination PE class and invalid copies of questionnaire are removed to make total 489 valid copies, with the effective retrieval rate $96.3 \%$, including 221 males (45.2\%) and 286 females (54.8\%), 115 freshmen, 118 sophomores, 126 juniors, and 130 seniors, as well as 286 from countryside and 203 from cities. The sample representativeness is favorable.

\section{Pretest Analysis}

Partial Least Squares (PLS), first proposed by Wold (1975) for econometric analysis but emphasized and popular in chemometry, is commonly used in management, marketing, and psychology. PLS defines a component structure with the linear integration of variables and, with regression principle, to explain and test the prediction and explanation among components that it is called Component-Based Structural Equation Modeling. PLS aims to acquire the maximum prediction among components. Components in the model are not the same as the properties of psychological dimension that the variable allocation is not restricted by normal assumptions that it is called soft modeling. PLS is suitable for solving the prediction of variables and exploring the theoretical model that it is utilized in this study for selecting the information in the pretest scale and exploring the attitude model.

\section{Result and Analysis of Pretest Scale}

Combining domestic and international research and experts' opinions with the teaching situations and characteristics of college three-self-determination PE class as well as college students' reflection to PE effect, 7 domestic college students' three-self-determination PE class teaching goals are confirmed, covering course cognition, social behaviors, health and safety, leisure life, sports knowledge, sports techniques, and physical development. Total 29 questions related to domestic college students' attitudes towards three-self-determination PE class are compiled for the 7-point simplified scale. It contains 6 questions about attitudes towards course cognition, 4 questions about attitudes towards social behaviors, 8 questions about attitudes towards health and safety, 2 questions about attitudes towards leisure life, 3 questions about attitudes towards sports knowledge, 3 questions about attitudes towards sports technique, and 3 questions about attitudes towards physical development. The research variables are reflective indices; questions with the same or similar contents present exchangeability; and, questions without changing the idea of dimensions are removed. Fornell and Larker (1981) suggested the structural validity with the factor loadings $>.70$. In this case, the data analyses show that the factor loadings of T1, T2, T4, K3, and SK1 in the pretest scale do not achieve the standard .70 that they are removed. The rest questions present the factor loadings in .74 .95, larger than .70, the composite reliability in .93 .97, larger than .70, the average of variance extracted in .77 .8, larger than .50, and the Cronbach's a in .82 .96, larger than .70, reaching the ideal standards. It reveals favorable reliability and convergent validity after removing 7 questions not achieving the standard. As a result, they should be remained. The square roots of AVE of variables appears in .88 .95, larger than the standardized correlation coefficients of other variables, showing better discriminant validity among dimensions. The constructed PLS attitude model GOF=.76 is higher than .36, revealing the good fit of attitude model with the 7 dimensions. The pretest scale of attitudes towards three-self-determination PE class passes the exploratory analysis that confirmatory analysis could be further preceded.

\section{FORMAL TEST OF THE SCALE OF ATTITUDES TOWARDS THREE-SELF- DETERMINATION PE CLASS}

\section{Test Subject}

Total 2500 college students in Tsinghua University, Harbin Institute of Technology, Shanghai Jiao Tong University, Southeast University, Xiamen University, Shenzhen University, Sichuan University, Hunan Agricultural University, Chongqing Jiaotong University, Guangxi Normal University, Northwestern Polytechnical University, and Lanzhou University are classified, sampled, and tested. Total 2487 copies of questionnaire are retrieved, and 45 invalid copies are removed to make the effective 2442 copies. The valid samples are listed in Table 
Table 1. Analysis of demographic characteristics

\begin{tabular}{|c|c|c|c|c|c|c|c|}
\hline Variable & Group & No. of Times & Percentage & Variable & Group & No. of Times & Percentage \\
\hline \multirow{15}{*}{ Sports item } & Football & 178 & 7.3 & \multirow{2}{*}{ Gender } & Male & 1175 & 48.1 \\
\hline & Basketball & 229 & 9.4 & & Female & 1267 & 51.9 \\
\hline & Volleyball & 212 & 8.7 & \multirow{4}{*}{ Grade } & First grade & 595 & 24.4 \\
\hline & Tennis & 142 & 5.8 & & Second grade & 611 & 25.0 \\
\hline & Badminton & 186 & 7.6 & & Third grade & 622 & 25.5 \\
\hline & Table tennis & 125 & 5.1 & & Fourth grade & 614 & 25.1 \\
\hline & Soccer & 93 & 3.8 & \multirow{2}{*}{ Origin } & Countryside & 1119 & 45.8 \\
\hline & Cricket & 68 & 2.8 & & City & 1323 & 54.2 \\
\hline & Swimming & 149 & 6.1 & \multirow{7}{*}{$\begin{array}{c}\text { Distribution of } \\
\text { university }\end{array}$} & Northeast & 2 & 10.0 \\
\hline & Martial art & 127 & 5.2 & & North China & 4 & 20.0 \\
\hline & Tai Chi & 120 & 4.9 & & East China & 4 & 20.0 \\
\hline & Taekwondo & 181 & 7.4 & & South China & 3 & 15.0 \\
\hline & $\begin{array}{l}\text { Rhythmic } \\
\text { gymnastics }\end{array}$ & 212 & 8.7 & & Central China & 2 & 10.0 \\
\hline & Shape & 201 & 8.2 & & Southwest & 2 & 10.0 \\
\hline & Others & 219 & 9.0 & & Northwest & 3 & 15.0 \\
\hline
\end{tabular}

1. The sampled colleges and universities are broadly distributed, including 2 in northeast, 4 in north China, 4 in east China, 3 in south China, 2 in central China, 2 in southwest, and 3 in south east.

\section{Statistical Analysis}

Confirmatory Factor Analysis (CFA) is an important part of SEM (Structural Equation Modeling). The reduction of variables for CFA is revised from Kline's (2010) two-order model. The measurement model should be tested before evaluating the structure model. The complete SEM report could be preceded when the measurement of the fit of model is acceptable. SEM, as the technological integration of structure covariance, could develop and test the model and compare the fit of the opposition model and data generated from theories. As a result, it is suitable to precede SEM Confirmatory Factor Analysis and evaluate the fit of model structure with AMOS.

\section{Result and Analysis of Formal Test}

\section{Reliability and validity}

With Factor Analysis, the factor loadings of all dimensions appear in .69 .93, including "attitudes towards course cognition" (average variance extracted $=0.64, \mathrm{a}=0.83$ ), "attitudes towards social behavior" (average variance extracted=0.75, a=0.92), "attitudes towards health and safety" (average variance extracted=0.69, $a=0.95$ ), "attitudes towards physical development" (average variance extracted $=0.81, \mathrm{a}=0.93$ ), "attitudes towards sports knowledge" (average variance extracted $=0.58, \mathrm{a}=0.73$ ), "attitudes towards sports technique" (average variance extracted $=0.74$, $\mathrm{a}=0.85$ ), and "attitudes towards leisure life" (average variance extracted $=0.75, \mathrm{a}=0.86$ ).

\section{Discriminant validity of form scale}

The results are shown in Table 2. The square roots of AVE of dimensions on the diagonal are larger than the standardized correlation coefficients beyond the diagonal that there is discriminant validity among the 7 dimensions. 
Table 2. Discriminant validity analysis of formal scale

\begin{tabular}{|c|c|c|c|c|c|c|c|}
\hline & $\begin{array}{c}\text { Cognition } \\
\text { goal }\end{array}$ & $\begin{array}{c}\text { Social } \\
\text { behaviors goal }\end{array}$ & $\begin{array}{l}\text { Health and } \\
\text { safety goal }\end{array}$ & $\begin{array}{c}\text { Leisure life } \\
\text { goal }\end{array}$ & $\begin{array}{c}\text { Sports } \\
\text { knowledge goal }\end{array}$ & $\begin{array}{c}\text { Sports } \\
\text { techniques goal }\end{array}$ & $\begin{array}{c}\text { Physical } \\
\text { goal }\end{array}$ \\
\hline Cognition goal & .80 & & & & & & \\
\hline $\begin{array}{l}\text { Social behaviors } \\
\text { goal }\end{array}$ & -.15 & .87 & & & & & \\
\hline $\begin{array}{l}\text { Health and } \\
\text { safety goal }\end{array}$ & -.26 & .81 & .83 & & & & \\
\hline Leisure life goal & -.22 & .72 & .83 & .87 & & & \\
\hline $\begin{array}{l}\text { Sports } \\
\text { knowledge goal }\end{array}$ & -.08 & .67 & .71 & .69 & .76 & & \\
\hline $\begin{array}{l}\text { Sports } \\
\text { techniques goal }\end{array}$ & -.10 & .64 & .69 & .70 & .67 & .86 & \\
\hline Physical goal & -.13 & .71 & .78 & .76 & .66 & .76 & .84 \\
\hline
\end{tabular}

Note: The bold on the diagonal is the square roots of AVE, lower triangle is the Pearson correlation of factors

Table 3. Fit indices of attitude model

\begin{tabular}{cccc}
\hline Fit indices & Allowable range & Fit & Model fit judgment \\
\hline Chi-square & & 386.55 & \\
\hline Degree of freedom & & 245 & pass \\
\hline CFI & $>.9$ & .98 & pass \\
\hline RMSEA & $<.08$ & .07 & pass \\
\hline TLI & $>.9$ & .98 & pass \\
\hline GFI & $>.9$ & .96 & pass \\
\hline NFI & $>.9$ & .96 & pass \\
\hline$X^{2} / d f$ & $<3$ & 1.58 & pass \\
\hline AGFI & $>.8$ & .95 &
\end{tabular}

\section{Test of attitude model}

Since SEM samples more than 200 could easily result in large chi-square value to cause bad fit, the fit needs to be modified with Bootstrap. The modified fit of model is shown in Table 3, from which the fit indices pass the standards, showing the acceptability of the attitude model. 


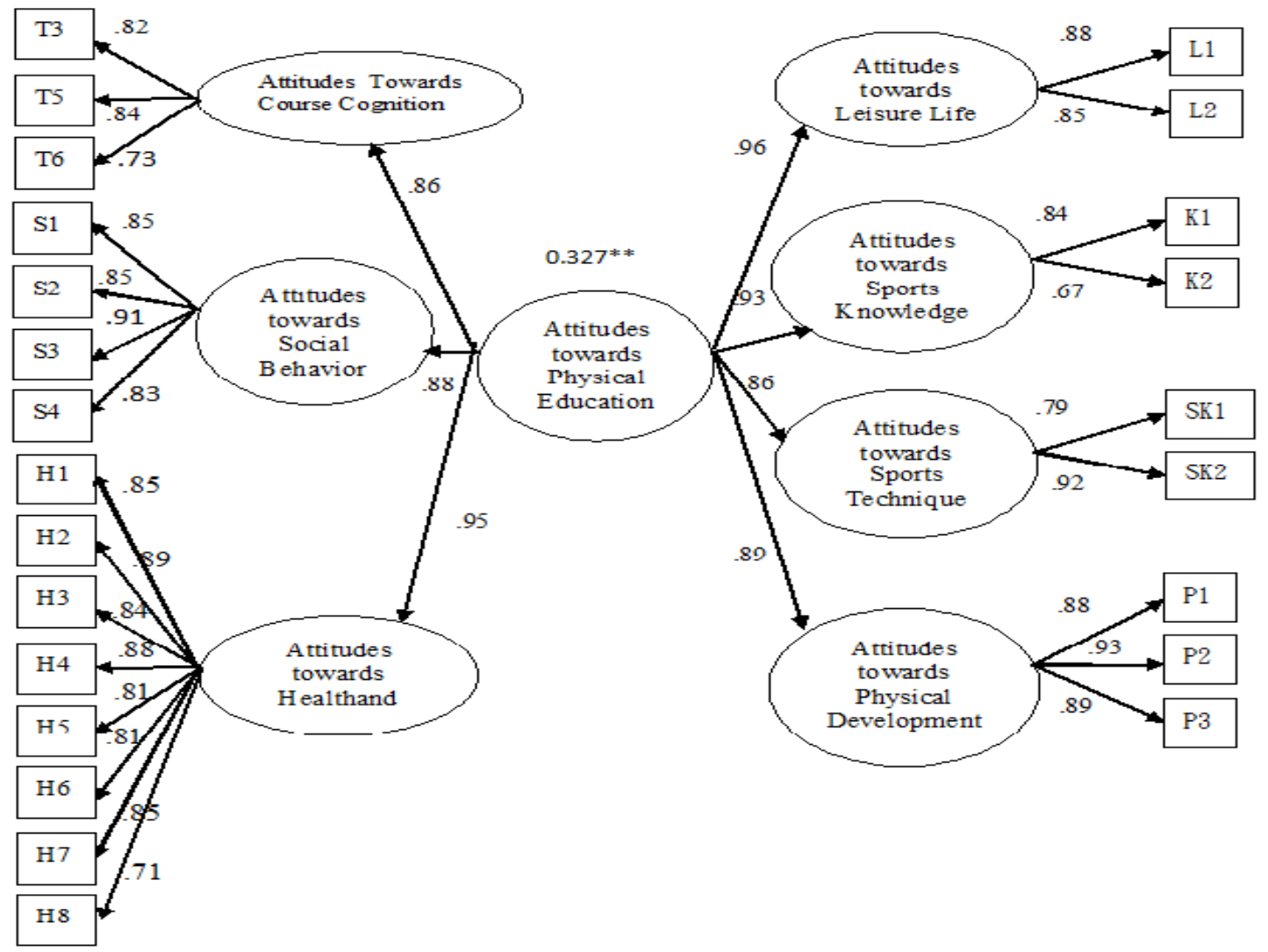

Figure 1. AMOS attitude model

Table 4. Cross validation data organization

\begin{tabular}{lccccc}
\hline Model & $\mathbf{\chi}^{\mathbf{2}}$ & $\mathbf{D f}$ & $\mathbf{\Delta d f}$ & $\mathbf{\Delta \mathbf { \chi } ^ { 2 }}$ & $\mathbf{P}$ \\
\hline Factor loadings & 14.97 & 17 & & 6 & 10.95 \\
\hline Structure coefficient & 25.92 & 23 & 1 & 2.24 & .30 \\
\hline Structure covariance & 28.16 & 24 & & .25 \\
\hline
\end{tabular}

\section{Cross validation test}

The samples are randomly divided into two groups to test the cross validation of the attitude model, containing the factor loadings, structure coefficient, and structure covariance of the measurement model. The model presents stability when there is no difference between the two sample groups. The results, Table 4, conform to the mild test, the data in two groups are homogeneous, and the two groups are equivalent, revealing no difference between two groups. The two groups present cross validation, and the attitude model shows stability.

\section{Sample estimation and statistical test}

RMSEA is used in this study for sampling, and the sample value is calculated according the degree of freedom 245 to make the minimum samples above 108. There are 2442 effective samples in this study, conforming to the requirement. The statistical test is better higher than .8 , and the statistical test of this study is 1 , showing good statistical test of this study. 
Table 5. Multivariate Analysis of Variance of gender and grade in attitudes towards three-self-determination PE class

\begin{tabular}{|c|c|c|c|c|c|c|c|c|c|}
\hline \multirow{2}{*}{ Factor } & \multicolumn{3}{|c|}{ Gender } & \multicolumn{3}{|c|}{ Grade } & \multicolumn{3}{|c|}{ Gender $\times$ Grade } \\
\hline & SS & df & $\mathbf{F}$ & SS & df & $\mathbf{F}$ & SS & df & $\mathbf{F}$ \\
\hline Attitudes towards course cognition & 13.99 & 1 & $6.14^{*}$ & 4.85 & 3 & 2.13 & 7.42 & 3 & $3.25^{\star}$ \\
\hline Attitudes towards social behavior & .15 & 1 & .12 & 2.52 & 3 & 2.10 & 1.06 & 3 & .88 \\
\hline Attitudes towards health and safety & .00 & 1 & .00 & 3.32 & 3 & $3.26^{*}$ & 1.40 & 3 & 1.38 \\
\hline Attitudes towards leisure life & 3.79 & 1 & 3.02 & 4.32 & 3 & $3.44^{\star}$ & 1.91 & 3 & 1.52 \\
\hline Attitudes towards sports knowledge & .15 & 1 & .12 & 3.47 & 3 & $2.70^{*}$ & 1.76 & 3 & 1.37 \\
\hline Attitudes towards sports technique & .36 & 1 & .25 & 3.33 & 3 & 2.33 & 2.26 & 3 & 1.58 \\
\hline Attitudes towards physical development & .53 & 1 & .44 & 2.03 & 3 & 1.69 & 1.53 & 3 & 1.27 \\
\hline
\end{tabular}

* stands for $P<1$

Table 6. National norms of college students' attitudes towards three-self-determination PE class

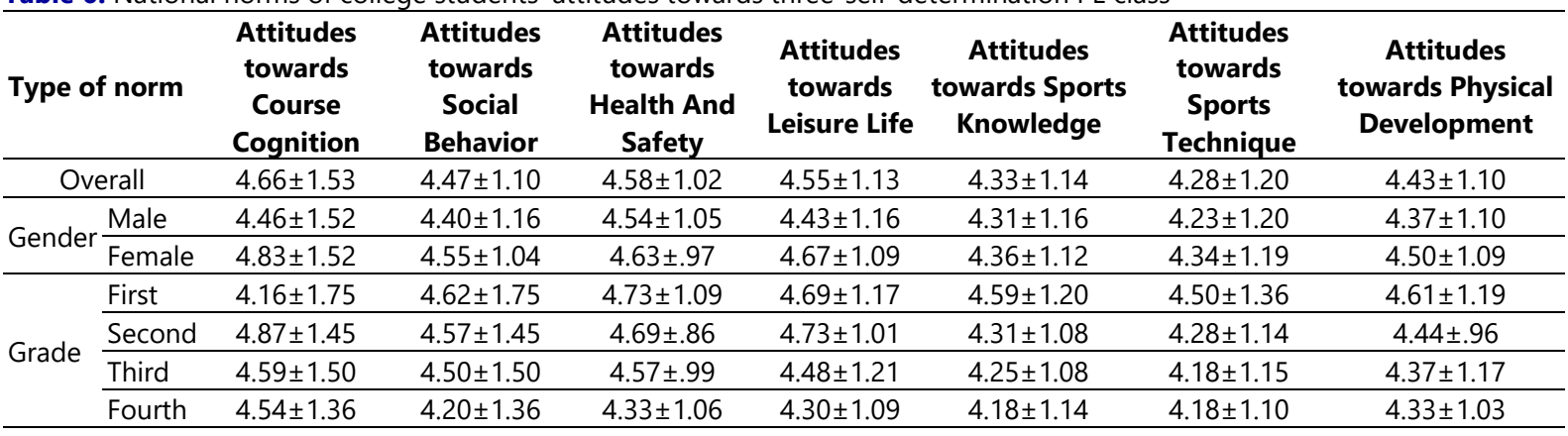

\section{NORMS OF COLLEGE STUDENTS' ATTITUDES TOWARDS THREE-SELF- DETERMINATION PE CLASS}

\section{Sample Distribution}

The normative samples, with formal test, appear 2442 valid copies and 812 valid copies acquired from the successive survey to make the total 3254 copies (samples are acquired from the previous 20 colleges and universities as well as 5 non-985 and 211 colleges and universities of Beijing Normal University (Zhuhai), Minnan Normal University, Anyang Institute of Technology, Ezhou Polytechnic, and Huanggang Normal College). The specific distribution shows 1676 females and 1578 males, 793 freshmen, 825 sophomores, 831 juniors, and 805 seniors, as well as 1566 from countryside and 1688 from cities. The sample representativeness is strong.

\section{Norm Establishment of College Students' Attitudes towards Three-Self-Determination PE Class}

Taking gender and grade as the arguments, the factors of attitudes towards three-self-determination PE class is evenly divided for Multivariate Analysis of Variance (MANOVA), Table 5. The results show significant differences in gender of the even division of attitudes towards course cognition, remarkable differences in grade of the even division of attitudes towards health and safety, attitudes towards leisure life, and attitudes towards sports knowledge, as well as notable interaction of gender×grade of the even distribution of attitudes towards course cognition. The multiple comparisons and simple effect test present that females appear higher attitudes towards course cognition than males; and, attitudes towards health and safety, attitudes towards leisure life, and attitudes towards sports knowledge decrease with increasing grade. The overall, gender, and grade norms of college students' attitudes towards three attitudes self-determination PE class are established from above analyses.

\section{Norm of College Students' Attitudes towards Three-Self-Determination PE Class}

Table 6 shows the overall norm, gender norm, and grade norm of college students' attitudes towards three-selfdetermination PE class. 


\section{DISCUSSION}

College three-self-determination PE class is the final stage of school physical education as well as the final opportunities for college students learning lifelong physical education and maintaining physical health before entering the society from the school system. For this reason, compiling the scale cutting in from college three-selfdetermination PE class teaching goals to understand college students' attitudes towards three-self-determination PE class and acquire the three-self-determination PE class teaching effect present the significant meaning for the complete college three-self-determination PE class teaching. It is also related to students' lifelong training and health and the key factor in the productivity of the nation and society and the expenditure of medical funds.

From college PE class teaching goals proposed under "National Teaching Guidelines for PE Course at the Level of General Universities and Colleges" issued by Ministry of Education, college PE class should achieve 5 goals of sports participation, sports skills, physical health, psychological health, and social adaptation. Some domestic researchers considered that college PE teaching goals should covered physical fitness, sports skills, knowledge of physical and health theories, and learning attitudes. Furthermore, domestic researchers also surveyed college students' PE class. For instance, Yeh (1994) indicated that ideal PE teaching goals should contain the cultivation of sports techniques, the training of physical fitness, the cultivation of social behaviors, the learning of professional sports knowledge, and the acquisition of sports fun. Tsai, Lin, and Liu (1998) discovered that college students' top PE class teaching goals contained the enhancement of personal health, the acquisition of physical and mental balanced development, the release of pressure, the establishment of sports habits, and the promotion of leisure life. Yang el al. (1994) pointed out the order of PE teaching goals approved by college students as the acquisition of health, the cultivation of sports habits, and the training of basic physical fitness. From above literatures, the statements of PE teaching goals from Ministry of Education, domestic researchers, and college students are distinct, but the basic agreement with PE teaching goals is consistent. The 7 major attitude structures in the scale cover above points of view that the 7 major dimensions are reasonable and present good structural validity.

Domestic research on scale compilation used to apply Exploratory Factor Analysis (EFA), but little utilize Structural Equation Modeling (SEM) for Confirmatory Factor Analysis (CFA) so that the consistency between the theoretical model and the actual data could not be effectively explored and verified; and, the cross-sample application stability of the scale cannot be tested. PLS (Partial Least Squares) is applied in this study to explore college students' attitudes towards three-self-determination PE class model. Information is selected from the pretest scale and SEM is utilized for Confirmatory Factor Analysis and testing the fit of attitude model that it is a new attempt for the reference of future researchers. From the attitude model explored with PLS, T1, T2, T4, K3, and SK1, which do not reach the factor loadings, are removed and the fit of attitude model GOF=.76 achieves the better standard. From SEM Confirmatory Factor Analysis and the test result of attitude model, all dimensions in the scale appear the factor loadings in .69 .93, the composite reliability (CR) in .73 .95, the average of variance extracted (AVE) in .58 .81, and the square root of AVE larger than the standardized correlation coefficients of various dimensions, explaining the good reliability and validity of the scale. The fit indices of attitude model pass the standards, revealing the acceptability of the attitude model which could be used for explaining the actual observed data. What is more, the attitude model passes the cross validation test, showing the cross-sample application stability of the scale. Based on above analyses, the college students' attitudes towards three-self-determination PE class simplified scale containing 7 major factors and 24 observation questions are eventually acquired.

From the national norm of college students' attitudes towards three-self-determination PE class, the average of college students' attitudes towards three-self-determination PE class is 4.50, and the overall evaluation of threeself-determination PE class is above the general standard, which are consistent with the past research results. Females present higher overall evaluation on college three-self-determination PE class and the evaluation of dimensions, and college students' overall evaluation and evaluation of dimensions of three-self-determination PE class reduce with increasing grade. It is possibly because females show stronger motivation on the participation in three-self-determination PE class; the higher class participation results in higher female evaluation. College students generally would complete three-self-determination PE class before being seniors that it is normal for the attitude evaluation decreasing with increasing grade.

\section{SUGGESTION}

A lot of domestic colleges and universities have established the PE course system "with the three-selfdetermination elective course as the body, the required course as the basis, the extra-curricular training as the supplement, and the competition training as the expansion" for the theoretical and practical innovation and breakthrough of college PE course systems. In this case, research on college students' attitudes towards three-selfdetermination PE class becomes primary. PLS (Partial Least Squares) is applied in this study to explore college students' attitudes towards three-self-determination PE class model and SEM is used for Confirmatory Factor Analysis and testing the fit of attitude model to eventually acquire college students' attitudes towards three-self- 
determination PE class simplified scale with good reliability and validity. The scale contains 7 major factors and 24 observation questions. It could be directly used for the measurement of college students' attitudes towards threeself-determination PE class. From the national norm of college students' attitudes towards three-self-determination PE class, the evaluation of three-self-determination PE class is above the general standard. It could be enhanced from the following directions.

(1) Colleges and universities should reinforce the research on the modernization of course establishment, timely assign teachers for learning and study, and establish some emerging PE projects to expand the course establishment, enhance the course novelty, and satisfy students' needs. Meanwhile, "three-selfdetermination" PE class should be reinforced the material construction. Particularly, the reinforcement of the research on and compilation of teaching outlines and teaching plans is the premise to guarantee the teaching quality.

(2) Teachers should be aware of the adjustment of the knowledge structure, expand the knowledge, reinforce the theory learning and business study, enhance the professional standards, and accurately find out the direction. Meanwhile, the network of "three-self-determination" course selection should be reinforced to enhance the teaching organization and management. The single assessment model should be changed to stress on the comprehensive evaluation in order to provide larger free space for students.

(3) With the great development in past years, domestic colleges and universities have established certain economic bases and presented the ability to improve and expand existing field and facilities. Colleges and universities should grasp such an opportunity to enlarge the PE field and facilities and gradually release the contradiction between students' requirement for course establishment and the lag of field and facility construction.

\section{ACKNOWLEDGEMENTS}

1. Fujian Province Education Department (Fujian higher education, No: 44, 2017), College of Applied Discipline construction field: Applied Economics application-oriented discipline cultivation project.

2. Fujian Provincial Education Department (Fujian education subject, No: 115, 2017), "Business Big data analysis and application of Fujian University key Laboratory" construction project.

\section{REFERENCES}

Alden, M. A. (1932). The Factors in the Required Physical Education Program that are Least Attractive to the College Girl. Research Quarterly for Exercise and Sport, 3(4), 97-107.

Carr, M. G. (1945). The Relationship between Success in Physical Education and Selected Attitudes Expressed by High School Freshmen Girls. Research Quarterly for Exercise and Sport, 16(3), 176-191.

Fornell, C., \& Larcker, D. F. (1981). Evaluating structural equation models with unobservable variables and measurement error. Journal of Marketing Research, 18(1), 39-50. https:/ / doi.org/10.2307/3151312

Kline, R. B. (2010). Principles and practice of structural equation modeling. Journal of the American Statistical Association, 101(12), 354-361.

Tsai, C.-B., Lin, L.-J., \& Liu, Y.-R. (1998). National Cheng Kung University PE course needs evaluation and survey. NCKU PE research collection, (4), 61-84.

Wold, H. (1975). Soft modelling by latent variables: the non-linear iterative partial least squares (NIPALS) approach. Perspectives in Probability and Statistics, 117-142. https:/ / doi.org/10.1017/S0021900200047604

Wu, S.-S. (2011). A study on the practice of "three-self-determination" teaching model in PE course of universities in Fujian Province. Shandong Sports Science \& Technology, 33(6), 70-72.

Yang, Z.-X., Chen, T.-C., Chen, H.-Y., Wu, H.-Y., Lan, B.-Y., Wang, J.-L., Liu, L.-Y., \& Chen, Q.-C. (1994). Opinion survey of the practice of university PE course. Sports \& Exercise Research, (18), 95-101.

Yeh, X.-Q. (1994). PE teaching goal and content. National Sports Quarterly, 23(4), 63-70. 


\section{APPENDIX}

\section{College Students' Attitudes towards Three-Self-Determination PE Class Simplified Scale}

\begin{tabular}{|c|c|c|c|}
\hline Factor & $\begin{array}{c}\text { Serial } \\
\text { no. }\end{array}$ & Question & Remark \\
\hline \multirow{6}{*}{$\begin{array}{l}\text { Attitudes } \\
\text { towards } \\
\text { course } \\
\text { cognition }\end{array}$} & T1 & Three-self-determination PE class is more effective than traditional PE class. & \\
\hline & $\mathrm{T} 2$ & Complete college PE teaching should contain three-self-determination PE teaching. & \\
\hline & T3 & $\begin{array}{l}\text { Physical training opportunities are adequate in daily life and learning that three-self-determination PE class is not } \\
\text { necessary. }\end{array}$ & \\
\hline & T4 & Modern education trend points out the necessity of college three-self-determination PE class teaching. & revised \\
\hline & T5 & Merely interested items are opened in PE required course, but not three-self-determination PE class. & \\
\hline & T6 & I would participate because three-self-determination PE class is a required credit. & \\
\hline \multirow{4}{*}{$\begin{array}{l}\text { Attitudes } \\
\text { towards } \\
\text { social } \\
\text { behavior }\end{array}$} & S1 & Three-self-determination PE class could provide actual teaching situations to develop sports spirit. & revised \\
\hline & S2 & Three-self-determination PE class could help develop good social behaviors. & \\
\hline & S3 & Three-self-determination PE class could train the brave, determined, and agile spirits. & \\
\hline & S4 & Three-self-determination PE class allows learning tolerance and obedience. & \\
\hline \multirow{8}{*}{$\begin{array}{l}\text { Attitudes } \\
\text { towards } \\
\text { health and } \\
\text { safety }\end{array}$} & $\mathrm{H} 1$ & Three-self-determination PE class could result in satisfactory and pleasant feelings. & \\
\hline & $\mathrm{H} 2$ & Three-self-determination PE class could inspire me to present self-confidence. & \\
\hline & $\mathrm{H} 3$ & Three-self-determination PE class could let me relax. & \\
\hline & $\mathrm{H} 4$ & Three-self-determination PE class is important to my physical training. & \\
\hline & $\mathrm{H} 5$ & Three-self-determination PE class allows me understanding the importance of sports to health. & revised \\
\hline & $\mathrm{H} 6$ & Self-selected three-self-determination PE class could enhance self-confidence. & revised \\
\hline & $\mathrm{H} 7$ & Three-self-determination PE class could help develop good figure. & \\
\hline & $\mathrm{H} 8$ & Three-self-determination PE class could enhance the health of physically weak students. & revised \\
\hline \multirow{2}{*}{$\begin{array}{c}\text { Attitudes } \\
\text { towards } \\
\text { leisure life }\end{array}$} & L1 & The teaching effect of three-self-determination PE class could have my life be more pleasant. & \\
\hline & L2 & Sports skills cultivated in three-self-determination PE class is valuable for the sports life after graduation. & revised \\
\hline \multirow{3}{*}{$\begin{array}{l}\text { Attitudes } \\
\text { towards } \\
\text { sports } \\
\text { knowledge }\end{array}$} & $\mathrm{K} 1$ & $\begin{array}{l}\text { Three-self-determination PE class shows explanations about the specific knowledge and rules of acquired sports } \\
\text { projects. }\end{array}$ & \\
\hline & $\mathrm{K} 2$ & Sports items learned in three-self-determination in PE class allow me becoming a professional sport audience. & revised \\
\hline & $\mathrm{K} 3$ & Mental activity (sports rules, PE theories) is not necessary for three-self-determination PE class. & \\
\hline \multirow{3}{*}{$\begin{array}{l}\text { Attitudes } \\
\text { towards } \\
\text { sports } \\
\text { technique }\end{array}$} & SK1 & $\begin{array}{l}\text { The participation of three-self-determination PE class merely trains techniques, but not mind (sports rules, PE } \\
\text { theories) }\end{array}$ & \\
\hline & SK2 & The participation in three-self-determination PE class allows me being familiar with the interested sports projects. & revised \\
\hline & SK3 & Three-self-determination PE class could help improve sports techniques. & \\
\hline \multirow{3}{*}{$\begin{array}{c}\text { Attitudes } \\
\text { towards } \\
\text { physical } \\
\text { development }\end{array}$} & P1 & The participation in three-self-determination PE class allows me showing more flexible responses to accidents. & \\
\hline & P2 & $\begin{array}{l}\text { The participation in three-self-determination PE class allows me engaging in learning and living in daily life with } \\
\text { enough strength and endurance. }\end{array}$ & revised \\
\hline & P3 & Three & \\
\hline
\end{tabular}

\section{http://www.ejmste.com}

